\title{
VARIÁVEIS QUE EXPLICAM O RETORNO DOS FUNDOS IMOBILIÁRIOS BRASILEIROS
}

\author{
Janaína Morais de Oliveira ${ }^{1}$ \\ Bruno Milani ${ }^{2}$ \\ Recebido em: 13 ago. 2019 \\ Aceito em: 07 fev. 2020
}

Como citar este artigo: OLIVEIRA, J.; MILANI, B. Variáveis que explicam o retorno dos fundos imobiliários brasileiros. Revista Visão: Gestão Organizacional, Caçador, SC, Brasil, v.9, n.1, p.17-33, jan./jun. 2020. ISSN 2238-9636. Disponível em:

<http://dx.doi.org/10.33362/visao.v9i1.2051>.

Resumo: Este artigo tem o objetivo de analisar o risco e o retorno do Fundos Imobiliários Brasileiros no período de janeiro de 2012 até dezembro de 2017. Para isso, foi adotada a metodologia da regressão stepwise, com a finalidade de compreender a influência de cada uma das variáveis explanatórias sobre a variável dependente IFIX, que serve como proxy para os Fundos Imobiliários. Como variáveis explicativas, foram utilizados diversos índices macroeconômicos e de mercado. Os resultados apontaram que o Índice Ibovespa é a única variável que explica o retorno dos Fundos Imobiliários quando a amostra é analisada em toda sua extensão. Porém, foi verificado também que há uma quebra estrutural, a partir da qual a locação de imóveis comercias e a venda de imóveis residenciais passa a explica-los.

Palavras-Chave: Fundos de Investimento Imobiliário. Mercado Imobiliário. Bolsa de Valores.

\section{VARIABLES THAT EXPLAIN THE RETURN OF BRAZILIAN REAL ESTATE FUNDS}

Abstract: This article aims to analyze the risk and return of Brazilian Real Estate Funds from January 2012 to December 2017. For this purpose, the stepwise regression methodology was adopted, in order to understand the influence of each on the variable IFIX, which serves as a proxy for Real Estate Funds. As explanatory variables, several macroeconomic and market indices were used. The results showed that the Ibovespa Index is the only variable that explains the return of Real Estate Funds when the sample is analyzed to its full extent. However, it was also found that there is a structural break, from which the rental of commercial real estate and the sale of residential real estate explains them.

Keywords: Real Estate Investment Funds. Real Estate Market. Stock Market.

\footnotetext{
${ }^{1}$ Bacharel em Administração pelo Instituto Federal de Educação, Ciência e Tecnologia Farroupillha - Campus São Vicente do Sul (IFFar-SVS). E-mail: janaina.moraisdeoliveira@hotmail.com.

${ }^{2}$ Doutor em Administração pelo Programa de Pós-Graduação em Administração da Universidade Federal de Santa Maria (PPGA-UFSM). Professor do Instituto Federal de Educação, Ciência e Tecnologia Farroupillha - Campus São Vicente do Sul (IFFar-SVS). E-mail: brunoprofess@gmail.com.
} 


\section{INTRODUÇÃO}

O mercado imobiliário no Brasil foi impulsionado nos últimos anos pela valorização dos aluguéis e preço dos imóveis residenciais e comerciais, tornando-se maior o número de investidores no segmento imobiliário devido aos avanços macroeconômicos obtidos pelo país.

Segundo dados apresentados pela ANBIMA, os fundos de investimentos obtiveram a maior captação líquida da história: foram $\mathrm{R} \$ 259,8$ bilhões no ano de 2017 , contra $\mathrm{R} \$ 130,6$ bilhões registrados em 2016. Tendo como principais fatores a queda da inflação e dos juros como estímulo neste segmento.

Neste contexto, há reflexos no desenvolvimento da economia do país com os juros menores no mercado e com a criação da Instrução 409/04 pela Comissão de Valores Mobiliários (CVM), ampliando o escopo de atuação dos fundos de investimentos. Dessa forma, viabilizou-se o investimento nos Fundos de Investimentos Imobiliários (FIIs). Este produto do mercado financeiro permite que investidores optem por fundos com carteiras conforme as perspectivas de risco e retorno dos investimentos em imóveis.

Todavia com produtos mais acessíveis a todos os bolsos, qualquer pessoa pode ser tornar um investidor imobiliário, motivo que levou os Fll ganharem maior destaque no âmbito dos investimentos, com aumento de aplicações por pessoas físicas.

Uma das principais vantagens ao investir em cotas dos Fll é a diluição do risco, por englobar a participação em diversos empreendimentos (casas, apartamentos, hotéis, shoppings, etc.). Outro ponto positivo, para os que buscam alternativas diferentes de diversificar seus investimentos e obter maior rentabilidade, é contar com um profissional qualificado e responsável pela gestão do fundo, sem o investidor se preocupar em administrálo.

Por outro lado, o dinheiro aplicado em Flls não é protegido pelo Fundo Garantidor de Crédito ( $F G C$ ), entidade responsável pelo patrimônio dos cotistas, que garante a recuperação de depósito ou créditos mantidos por bancos. Ao contrário dos Fundos de Investimentos que são fiscalizados pela Comissão de Valores Mobiliários (CVM).

Devido à crescente importância deste produto financeiro, este trabalho tem como objetivo geral verificar quais variáveis explicam o retorno dos Fundos de Investimentos Imobiliários brasileiros no período de 2012 a 2017.

\section{REFERENCIAL TEÓRICO}

\section{FUNDOS DE INVESTIMENTO}

A instrução normativa № 409/04, art. 2o, da CVM, caracteriza o Fundo de Investimento 
como "uma comunhão de recursos, constituída sob a forma de condomínio, destinado à aplicação em títulos mobiliários, bem como em quaisquer outros ativos disponíveis no mercado financeiro e de capitais".

Os Fundos de investimentos são combinações de recursos de indivíduos e/ou empresas com o propósito de investimento em uma carteira diversificada de ativos, de modo a oferecer oportunidade aos pequenos investidores de diversificar o risco de seus investimentos (MOTA, 2013).

Nesta perspectiva, o fundo de investimento proporciona aplicação de recursos financeiros em carteiras de maior rentabilidade para o investidor pessoa física ou jurídica, explicam Trindade e Malaquias (2015).

Os Fundos de Investimentos classificam-se, como previstos na Instrução CVM nำ55, de 17 de dezembro de 2014, art. 108, seção VI, conforme a composição de suas carteiras, de acordo com o risco que será, em regra, assumido pelo gestor: (I) Fundo de Renda Fixa; (II) Fundo de Ações; (III) Fundo Multimercado; e (IV) Fundo Cambial.

Estes fundos estão divididos em dois grupos: Fundos de Renda Fixa e Fundos de Renda Variável, tendo como principal diferença a rentabilidade dos recursos aplicados, acrescenta Trindade e Malaquias (2015). Os Fundos de Renda Fixa têm seus valores ditados no mercado financeiro e os de Renda Variável oscilam conforme as condições do mercado financeiro, portanto, apresentam risco maior, complementa Mota (2013).

Resumindo, os Fundos de Renda Variável são caracterizados como investimentos mais agressivos, enquanto os Fundos de Renda Fixa podem ser mais adequados a investidores mais conservadores, por apresentarem menor volatilidade em sua rentabilidade (TRINDADE e MALAQUIAS, 2015). Dessa forma, Pitta (2000) explica que essa diferenciação no risco de cada carteira do Fundo de Investimento fomenta o interesse dos investidores em fundos com melhor relação risco-retorno.

Os Fundos de Investimentos podem ser organizados sob a forma de condomínio aberto, os quais de acordo com a Instrução 409/04, art. 5ํ, podem efetuar o resgate das cotas a qualquer momento, ou fechado, cujo resgate se dá somente após o término do prazo determinado.

Nos fundos abertos é permitida a entrada de novos cotistas ou o aumento da participação dos antigos por meio de novos investimentos, assim como é permitida a saída de cotistas, por meio de resgates de cotas, isto é, mediante a venda de ativos do fundo para entrega do valor correspondente ao cotista que efetuou o resgate, total ou parcial, de suas cotas. Já nos fundos fechados, a entrada e a saída de cotistas não é permitida. Após o período de captação de recursos pelo fundo, não são admitidos novos cotistas nem novos investimentos pelos antigos cotistas. Além disso, também não é admitido o resgate de cotas por decisão do cotista, que tem que vender suas cotas a terceiros se quiser receber o seu valor antes do encerramento do fundo (Portal Investidor, CVM). 
As cotas podem ter tempo determinado ou indeterminado, assim o cotista poderá ter o retorno do investimento em caso de liquidação deliberada pela assembleia geral de cotistas, com o término do prazo de duração dos Fll ou negociados no mercado secundário (MANGANOTTI, 2014).

\section{FUNDOS DE INVESTIMENTO IMOBILIÁRIOS}

A Comissão de Valores Imobiliários (CVM), entidade que regulamenta e fiscaliza os Fundos de Investimento Imobiliário no Brasil, conceitua em sua instrução 472/08, que o FII "é uma comunhão de recursos captados por meio do sistema de distribuição de valores mobiliários e destinados à aplicação em empreendimentos imobiliários".

O investimento em ativos desses empreendimentos imobiliários se dá por meio de "investimento direto em ativos reais imobiliários", tendo como renda o aluguel dos bens imóveis e/ou "valores mobiliários lastreados por ativos imobiliários", no caso dos Certificados de Recebíveis Imobiliários (CRI), Letras de Crédito Imobiliário (LCI), Letras Hipotecárias (LH) e ações de outras companhias imobiliárias, esclarece Frade (2015).

Na visão de Mota (2013), os Fundos de Investimentos Imobiliário (Flls) são formados por grupos de investidores que adquirem cotas negociadas na bolsa de valores como forma de captação de recursos, os quais são utilizados em empreendimentos imobiliários. Em outras palavras, conforme Mizuno et al (2011), esta comunhão de recursos tem por objetivo obter ganhos financeiros de renda variável.

Segundo ainda o mesmo autor, a rentabilidade do investidor dependerá da locação, venda ou arrendamento dos imóveis adquiridos no mercado imobiliário. Em adição, o retorno do capital, como na maioria dos fundos, acontece por meio da distribuição de resultados ou da venda das cotas (GUIMARÃES, 2013).

Efetivamente a busca por fundos imobiliários é a possibilidade de investir em qualquer tipo de empreendimento, tendo sua rentabilidade com o "valor dos aluguéis" e/ou "valorização dos imóveis na bolsa", destaca Valim (2013).

As cotas podem ser negociadas em mercado de balcão organizado ou bolsa de valores, sendo que essa última propicia maior liquidez para os ativos (FRADE, 2015). Acrescenta-se também que esses ativos de renda variável quando negociadas na bolsa de valores podem se valorizar ou desvalorizar, dependendo dos fatores de mercado, exemplifica Scolese et al (2015).

Em síntese, Mota (2013) esclarece que os Fundos Imobiliários são condomínios fechados que reúnem recursos de um conjunto de investidores.

O Fll é constituído sob a forma de condomínio fechado, em que não é permitido ao investidor resgatar as cotas antes de decorrido o prazo de duração do fundo. A maior parte dos Flls tem prazo de duração indeterminado, ou seja, não é estabelecida uma data para a sua liquidação. Nesse caso, se o investidor decidir sair do investimento, somente poderá fazê-lo através da venda de suas cotas no mercado secundário 
(BM\&FBOVESPA).

De acordo com a CVM existem três principais riscos associadas à aplicação em cotas de Flls: o risco de mercado, o risco de crédito e o risco de liquidez.

O primeiro é o decorrente das oscilações nos preços dos títulos que compõem a carteira do fundo. Já o risco de crédito se refere à certeza sobre a liquidação do título na data de vencimento. Por fim, existe o risco de liquidez, que tanto pode ser dos ativos quanto das cotas que compõem o fundo (Portal do Investidor, CVM).

A Associação Brasileira das Entidades dos Mercados Financeiros e de Capitais (ANBIMA) aponta também o risco macroeconômico e o risco de vacância que afetam a volatilidade da carteira de investimento. Os riscos de mercado financeiro referem-se aos fatores macroeconômicos, como eventos de natureza política, econômica e financeira que alteram a ordem atual, incluindo variações nas taxas de juros, modificações da legislação, entre outros (MANGANOTTI, 2014). Fonseca et al (2007), acrescentam que o risco é maior tanto quanto o retorno esperado, sendo fundamental o gestor incorporar o risco na avaliação da performance do fundo.

Recomenda-se que o investidor analise o desempenho do Fundo por meio do Índice de Fundos de Investimentos Imobiliários (IFIX), indicador de desempenho das cotações negociadas no mercado imobiliário, esclarece Frade (2015). O IFIX permite aos investidores analisar o desempenho dos fundos imobiliários através de um único indicador (GUIMARÃES, 2015).

Na definição da ANBIMA (2014, p.47), "o IFIX reflete não apenas as variações do valor das cotas como também o impacto da distribuição dos rendimentos do fundo, sendo considerado, por isso, um índice que avalia o retorno total do investimento em cotas de fundos imobiliários em sua carteira".

\section{ESTUDOS ANTERIORES}

Frade (2015) faz aplicação do método de Valores Auto Regressivos (VAR) com o objetivo de analisar as variações nas taxas de juros em relação ao retorno dos Flls. Para resolver esse problema, o autor optou por duas alternativas: na primeira parte, explorou a relação entre o IFIX e as variações na taxa Selic, observando uma relação negativa entre elas; em uma segunda parte, buscou analisar o efeito de diferentes taxas de juros utilizando da Análise dos Componentes Principais na estrutura da curva de juros. O trabalho conclui que o IFIX apresenta resposta significativamente negativa ao impulso de uma variação positiva no nível da curva de juros, enquanto não apresenta variação significativa para variações na inclinação.

No estudo de Trindade e Malaquias (2015) foi analisado o desempenho dos Flls brasileiros entre fevereiro de 2013 a janeiro de 2014, utilizando como referência a divisão entre 
fundos de renda fixa e fundos de renda variável. Os autores utilizaram o IBOVESPA como benchmark para fundos de renda variável e a Selic como benchmark para fundos de renda fixa. Os resultados indicaram que, entre as duas modalidades analisadas, os fundos de renda variável conseguiram alcançar médias de rentabilidade um pouco superiores em relação aos fundos de renda fixa, proporcionado, especificamente pelos resultados alcançados pelos fundos multimercado.

No estudo de Scolese et al (2015), foram analisados os índices do mercado financeiro brasileiro do segmento de renda fixa, de renda variável e do segmento imobiliário para o período de 2011 a 2015, utilizando as seguintes variáveis: IMA-B5, IMA-B5+, IBOVESPA, IDIV, IRF-M e IGMI-C. Como conclusão, os índices de renda fixa IRF-M e IMA-B5, mostraram que os retornos dos Flls são influenciados pelo comportamento das Taxas de Juros do mercado e pela inflação. O IBOVESPA apresentou influência positiva, conforme esperado.

Manganotti (2014) buscou comparar o retorno dos Fundos de Investimento em Renda Fixa com os retornos de imóveis comerciais físicos no período de 13 anos. O índice Ibovespa destacou-se, pois apresentou significância em alguns fundos e dentro deste universo o coeficiente resultante foi positivo. Já o retorno mensal do Certificado de Depósito Interbancário (CDI) obteve o resultado contrário em todos os resultados analisados, tendo coeficiente negativo em relação aos Fundo de Investimento em Renda Fixa.

Yokoyama (2014) analisou as variáveis que influenciam os retornos dos fundos imobiliários brasileiros para uma amostra de fundos listados em Bolsa de Valores de São Paulo, no período de 2008-2013. De acordo com resultados, os fundos imobiliários da amostra apresentaram maior retorno em relação aos demais mercados, exceto em comparação com o mercado imobiliário, porém com menor risco. As análises de correlação, regressão e decomposição da variância indicaram que o mercado de ações e o mercado imobiliário direto, em geral, geram coeficientes significativos no modelo, porém explicam apenas cerca de 15\% da volatilidade dos retornos dos fundos da amostra.

Guimarães (2013) buscou analisar carteiras de fundos de acordo com a rentabilidade, segregando os fundos mais rentáveis, menos rentáveis e intermediários, utilizando o Sistema Quantum Axis. A análise dessas carteiras foi feita por duas metodologias: a análise de persistências e os modelos de performance absoluta. Os resultados mostram que carteiras de fundos de maior rentabilidade apresentam persistência nas duas metodologias utilizadas. Carteiras com rentabilidade intermediária têm desempenho persistentemente superior ao mercado, mas com volatilidade maior que as carteiras de maior rentabilidade.

O trabalho de Fiorini (2012) tem como objetivo apresentar o desempenho dos Flls com cotas negociadas em bolsa. Os Fundos Imobiliários de gestão ativa, sem imóvel definido no Oferta Pública Inicial (IPO), que investem em lajes corporativas, são os mais rentáveis. Fundos com imóveis definidos são utilizados como saída de investimento e não são um bom 
investimento. Já os fundos que investem em títulos de recebíveis imobiliários (CRIs, LHs e LCls) não apresentaram rentabilidade estatisticamente diferentes dos demais Flls de gestão ativa, porém são investimentos interessantes, pois apresentam boa rentabilidade dos fundos de gestão ativa e usufruem dos mesmos benefícios fiscais.

Mizuno et al (2011) em seu artigo objetivou analisar a eficiência do uso dos recursos dos Fundos de Investimentos Imobiliários utilizando a métrica de Análise Envoltória de Dados (DEA) com aderência à teoria da Visão Baseada em Recursos. Ao analisar os resultados obtidos, constata-se que a métrica DEA permite a análise de um determinado Fundo em conjunto com os demais, ou seja, no segmento no qual está inserido. Os resultados deste estudo sugerem que os Fundos são mais eficientes no uso de recursos Patrimônio Líquido e Ativo Total do que o uso de Receitas.

Pais (2011) buscou analisar a rentabilidade dos Flls categorizados como FIIA (Fundo de Investimento Aberto), FIIF (Fundo de Investimento Fechado) e o IPC (Índice de Preço ao Consumidor). O autor utilizou de ferramentas estatísticas para análise dos resultados: o teste de normalidade, teste autocorrelação, teste de estacionaridade e correlação. O FIIA e FIIF obtiveram resultados diferentes na maior parte das características analisadas.

Fonseca et al (2007) buscou analisar o retorno dos Fundos de Renda Fixa e de Renda Variável. Os resultados de seu trabalho mostraram que os Fundos de Renda Variável tiveram retornos maiores no período de maio de 2001 a maio de 2006. No entanto, em termos de riscoretorno esses fundos não tiveram bom desempenho em comparação aos Fundos de Renda Fixa, muito em função da alta volatilidade do Ibovespa no período e também das altas taxas de Juros - CDI e Selic - que balizam as operações no mercado de renda fixa doméstico.

No trabalho de Pitta (2000), percebe-se que o investimento em imóveis apresenta retornos muito menos voláteis que os verificados no mercado de ações. Foi utilizado o coeficiente de variação como ferramenta para comparação entre alternativas de investimentos, concluindo que, para os dados levantados no período de 1980 a 1999, o investimento imobiliário apresentou o menor risco por unidade de retorno.

\section{MÉTODO}

O objetivo deste estudo consiste na análise das variáveis que explicam o risco e o retorno dos Flls brasileiros. A abordagem utilizada é quantitativa, por aplicar ferramentas estatísticas, sendo utilizado o software Gretl para a análise dos dados.

De acordo com Fonseca (2002, p.20), a pesquisa quantitativa utiliza "linguagem matemática" para compreender e facilitar a mensuração dos dados coletados. Quanto aos objetivos, classifica-se como descritiva. Nesse tipo de pesquisa, os fatos são observados, registrados, analisados, classificados e interpretados, sem que o pesquisador interfira neles 
(ANDRADE, 2010, p.112). Quanto à natureza, esta pesquisa classifica-se como sendo aplicada.

Já o procedimento técnico utilizado para a coleta de dados é a pesquisa documental. A pesquisa documental utiliza de outras fontes documentais primárias para a construção do entendimento sobre o objeto de estudo, ou seja, "pode ser constituído por qualquer objeto capaz de comprovar algum fato ou acontecimento" (GIL, 2016, p.31).

Para atender ao objetivo da pesquisa, a variação do Índice IFIX foi utilizado como proxy da rentabilidade dos Fundos Imobiliários, portanto a variável dependente deste estudo. Diversos outros índices foram utilizados como variáveis explanatórias, para explicar a variação do IFIX.

Os dados referentes a Taxa Selic, INPC, IPCA e IGP-M, foram extraídos do Sistema Gerenciador de Séries Temporais (SGS), banco de dados do Banco Central do Brasil; os índices IFIX, IBO e IMOB estão disponíveis online no site da BMF\&BOVESPA; e o FIPEZAP Comercial e Residencial foram coletados por meio de relatórios publicados no site da Fundação Instituto de Pesquisas Econômicas (FIPE). Os dados são de frequência mensal e inicia em janeiro de 2012 e vai até dezembro de 2017. O Quadro 1 apresenta a descrição das variáveis.

Quadro 1 - Descrição das Variáveis

\begin{tabular}{|c|c|c|c|}
\hline & Variáveis & Fonte & Descrição \\
\hline Dependente & IFIX & $\begin{array}{l}\text { Bolsa de Valores de São Paulo } \\
\text { - BM\&BOVESPA }\end{array}$ & $\begin{array}{l}\text { Variação IFIX (Índice de Fundos de } \\
\text { Investimento Imobiliário) }\end{array}$ \\
\hline \multirow{10}{*}{ Explanatórias } & $\mathrm{IMOB}$ & $\begin{array}{l}\text { Bolsa de Valores de São Paulo } \\
\text { - BM\&BOVESPA }\end{array}$ & Variação do IMOB (Índice Imobiliário) \\
\hline & SELIC & Banco Central do Brasil - BCB & $\begin{array}{l}\text { Variação SELIC (Sistema Especial de } \\
\text { Liquidação e Custódia) }\end{array}$ \\
\hline & INPC & Banco Central do Brasil - BCB & $\begin{array}{l}\text { Variação INPC (Índice Nacional de } \\
\text { Preços ao Consumidor) }\end{array}$ \\
\hline & IPCA & Banco Central do Brasil - BCB & $\begin{array}{l}\text { Variação IPCA (Índice Nacional de } \\
\text { Preços ao Consumidor Amplo) }\end{array}$ \\
\hline & IPCA Hab & Banco Central do Brasil - BCB & $\begin{array}{l}\text { Variação IPCA Hab. (Índice Nacional } \\
\text { de Preços ao Consumidor Amplo } \\
\text { Habitação) }\end{array}$ \\
\hline & IPC Hab & Banco Central do Brasil - BCB & $\begin{array}{l}\text { Variação IPC Hab. (índice de Preço ao } \\
\text { Consumidor Habitação) }\end{array}$ \\
\hline & IGP-M & Banco Central do Brasil - BCB & $\begin{array}{l}\text { Variação IGP-M (Índice Geral de } \\
\text { Preços do Mercado) }\end{array}$ \\
\hline & $\begin{array}{l}\text { FIPEZAP } \\
\text { Com_Venda }\end{array}$ & $\begin{array}{l}\text { Fundação Instituto de } \\
\text { Pesquisas Econômicas - FIPE }\end{array}$ & $\begin{array}{l}\text { Variação FIPEZAP (Índice FipeZap de } \\
\text { Preços de Imóveis Anunciados } \\
\text { Comercial Venda) }\end{array}$ \\
\hline & FIPEZAP Com_Loc & $\begin{array}{l}\text { Fundação Instituto de } \\
\text { Pesquisas Econômicas - FIPE }\end{array}$ & $\begin{array}{l}\text { Variação FIPEZAP (Índice FipeZap de } \\
\text { Preços de Imóveis Anunciados } \\
\text { Comercial Locação) }\end{array}$ \\
\hline & $\begin{array}{l}\text { FIPEZAP } \\
\text { Res_Venda }\end{array}$ & $\begin{array}{l}\text { Fundação Instituto de } \\
\text { Pesquisas Econômicas - FIPE }\end{array}$ & $\begin{array}{l}\text { Variação FIPEZAP (Índice FipeZap de } \\
\text { Preços de Imóveis Anunciados } \\
\text { Residencial Venda) }\end{array}$ \\
\hline
\end{tabular}




\begin{tabular}{|l|l|l|l|}
\hline & FIPEZAP Res_Loc & $\begin{array}{l}\text { Fundação Instituto de } \\
\text { Pesquisas Econômicas - FIPE }\end{array}$ & $\begin{array}{l}\text { Variação FIPEZAP (Índice FipeZap de } \\
\text { Preços de Imóveis Anunciados } \\
\text { Residencial Locação) }\end{array}$ \\
\cline { 2 - 3 } & IBO & $\begin{array}{l}\text { Bolsa de Valores de São Paulo } \\
\text { - BMF\&BOVESPA }\end{array}$ & \begin{tabular}{l} 
Variação IBO (Índice Ibovespa) \\
\hline
\end{tabular}
\end{tabular}

Fonte: elaborado pelos autores.

Primeiramente buscou-se analisar a estacionaridade das séries temporais determinadas pelo Teste ADF-GLS e o Teste KPSS e, posteriormente, a estimação da regressão linear stepwise. Os resultados são expostos na Seção 4.

\section{ANÁLISE DOS RESULTADOS}

A Figura 01 demonstra que o IFIX mensal teve pouca oscilação entre os anos de 2012 até 2015, apresentando maior crescimento após este período. O teste de Chow para quebra estrutural aponta que uma quebra no mês de junho de 2015, ao grau de significância de 7\%. Deste modo, optou-se por realizar uma regressão linear stepwise para o período amostral completo e uma segunda regressão para o subperíodo compreendido entre junho de 2015 e dezembro de 2017.

Figura 01 - Variação do IFIX entre 2012 e 2017

\section{IFIX}

250,00

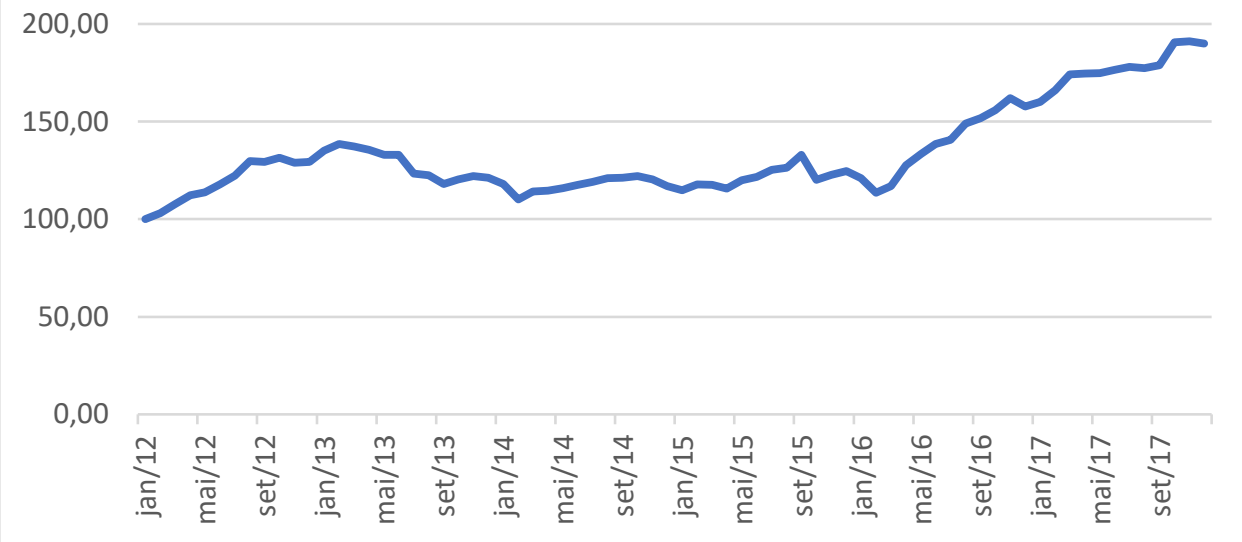

Fonte: elaborado pelos autores.

Para os dados em estudos aplicaram-se dois tipos de teste de raiz unitária: teste de ADF-GLS (Augmented Dickley - Fuller) e o teste KPSS, de modo a certificar a estacionaridade da série temporal, conforme Tabela 01. Segundo Bussab (2009, p.330), os testes estatísticos de hipóteses são ferramentas que tem finalidade de verificar dentro do método utilizado e com base nos resultados amostrais a decisão entre aceitar ou rejeitar uma hipótese. 
Neste caso, o Teste ADF-GLS toma como hipótese nula $\left(H_{0}\right)$ a presença de uma raiz unitária e a hipótese alternativa $\left(H_{a}\right)$ quando a série é estacionária. O teste irá levar à aceitação ou rejeição da hipótese $H_{0}$, o que corresponde, portanto, a diferença entre o valor hipotético e o estimado, considerando o nível de $\alpha=5 \%$ de significância. Para Gujarati e Porter (2011, p.134), "um teste de significância é um procedimento em que os resultados amostrais são usados para verificar a veracidade ou a falsidade de uma hipótese nula", sendo o $p$-valor o nível de significância observado.

O teste de KPSS tem a mesma finalidade do teste de ADF-GLS, determinar a estacionaridade numa série temporal, entretanto, a análise da presença de raiz unitária se dá pela hipótese alternativa $\left(H_{a}\right)$, enquanto, na hipótese nula $\left(H_{0}\right)$ a série é estacionária. Os coeficientes obtidos pelos testes de raiz unitária são apresentados na Tabela 01.

Tabela 01: Testes de Raiz Unitária ADF-GLS e KPSS

\begin{tabular}{l|l|l}
\hline Variáveis & ADF-GLS & KPSS \\
\hline IFIX & 0,2318 & 0,1951 \\
\hline IMOB & 0,5282 & 0,1888 \\
\hline SELIC & 0,3239 & 0,8408 \\
\hline INPC & 0,0063 & 0,2752 \\
\hline IPCA & 0,1881 & 0,2443 \\
\hline IPCA Hab & 0,0605 & 0,1671 \\
\hline IPC Hab & 0,0591 & 0,3184 \\
\hline IGP-M & 0,0026 & 0,1895 \\
\hline FIPEZAP_Com_Venda & 0,0471 & 1,5366 \\
\hline FIPEZAP_Com_Loc & 0,0571 & 1,2029 \\
\hline FIPEZAP_Res_Venda & 0,5503 & 1,7273 \\
\hline FIPEZAP_Res_Loc & 0,6011 & 1,2851 \\
\hline IBO & $1,156 \mathrm{e}-005$ & 0,2157 \\
\hline FOnte: Elaborado pelos autores & &
\end{tabular}

Fonte: Elaborado pelos autores

Da análise dos resultados do Teste de ADF-GLS pode-se concluir que as variáveis independentes INPC, IGP-M e o FIPEZAP_Com_Venda, tem o valor de $p<0,05$, correspondendo a 0,0063, 0,0026 e 0,0471, respectivamente, evidenciando a rejeição da hipótese nula. Complementarmente, os resultados do Teste KPSS apontam que as variáveis SELIC, FIPEZAP_Com. Venda, FIPEZAP_Com_Loc., FIPEZAP_Res_Venda e FIPEZAP_Res_Loc. não são estacionárias. Os dois testes apontam nas demais variáveis independentes a presença de raiz unitária.

Verifica-se que o único resultado comum nos dois testes aplicados foi que a variável explanatória FIPEZAP_Com_Venda foi considerada não estacionária. Para resolver este problema, calculou-se sua primeira diferença. Optou-se por não diferenciar as demais variáveis. 


\section{REGRESSÃO LINEAR COM AMOSTRA COMPLETA}

Após uma estimação preliminar de regressão via stepwise, três variáveis foram consideradas significativas: Ibovespa, IPCA e INPC. No entanto, verificou-se, através do Fator de Inflação da Variância (FIV), que a regressão era espúria devido à multicolinearidade entre as últimas duas. Percebeu-se ainda que estas variáveis apresentavam coeficiente de correlação superior a 0,95. A partir disso, foram estimadas duas novas regressões, uma contendo a variável IPCA entre as explicativas e outra contendo a variável INPC, as quais não foram consideradas significativas em ambos casos. Optou-se por excluir a variável IPCA da base de dados, a fim de evitar o problema da multicolinearidade, e estimar nova regressão.

Figura 02: Resultado do Modelo de Mínimos Quadrado Ordinários

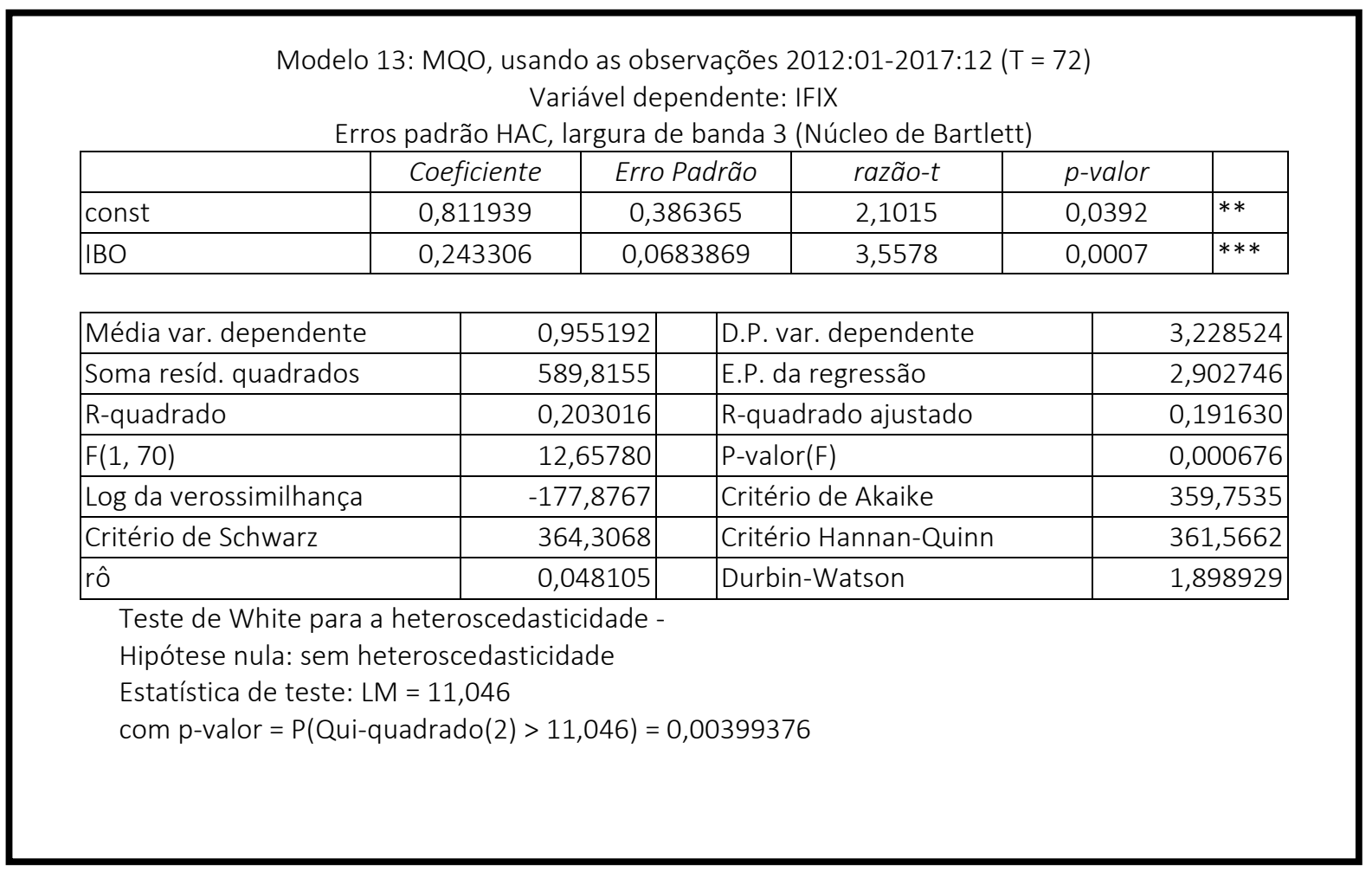

Fonte: Elaborado pelos autores no software Gretl.

A Figura 02 apresenta o output do software Gret/ com os coeficientes estimados pela nova regressão stepwise. Esta estimação inclui todas as variáveis explanatórias que constam no Quadro 1, exceto IPCA. Porém, apenas uma delas pode ser considerada significativa, ao grau de significância de $5 \%$.

Os resultados apontam que o índice Ibovespa explica o retorno dos Fundos de Investimento Imobiliários, representados pelo índice IFIX, com coeficiente de aproximadamente 0,2433 . Logo, no período analisado, a cada 1,0000\% de aumento do Índice Ibovespa, houve um amento de 0,2433\% nos Fundos Imobiliários. O valor de $r^{2}$ é de 0,2030, indicando que cerca de $20,30 \%$ da variância foi explicada. 
Conclui-se que os demais índices utilizados como variáveis explanatórias não explicam a variação do índice IFIX, gerando indícios de que, ao contrário do esperado, eles não servem como benchmark para os Flls, de forma que seu investidor assume riscos similares aos dos investimentos na bolsa de valores.

Aplicando o teste de heteroscedasticidade de White, não foram encontradas evidências de heteroscedasticidade, ou seja, não se rejeita a hipótese nula de homocedasticidade. Segundo Gujarati e Porter (2011, p.372), a heteroscedasticidade pode ocorrer como resultado da presença de dados discrepantes (outliers), erros de especificação ou assimetria na distribuição de um ou mais regressores. A análise do Fator de Inflacionamento da Variância não foi necessária, pois há apenas uma variável explanatória.

\section{REGRESSÃO LINEAR COM SUB AMOSTRA}

A Figura 3 apresenta os coeficientes estimados pela regressão linear stepwise realizada com o subperíodo amostral que vai de junho de 2015 e dezembro de 2017, totalizando 30 observações. Este período foi escolhido com base na quebra estrutural verificada anteriormente.

Figura 03: Resultado do Modelo de MQO com subamostra

\begin{tabular}{|c|c|c|c|c|c|c|}
\hline \multicolumn{7}{|c|}{$\begin{array}{l}\text { Modelo 20: MQO, usando as observações 2015:07-2017:12 ( }(\text { = 30) } \\
\text { Variável dependente: IFIX } \\
\text { Erros padrão HAC, largura de banda } 2 \text { (Núcleo de Bartlett) }\end{array}$} \\
\hline & Coeficiente & \multicolumn{2}{|c|}{ Erro Padrão } & razão-t & \multicolumn{2}{|l|}{$p$-valor } \\
\hline const & 0,651068 & \multicolumn{2}{|c|}{0,584984} & 1,1130 & 0,2759 & \\
\hline FIPEZAP_Com_Loc & $-1,05426$ & \multicolumn{2}{|c|}{0,476345} & $-2,2132$ & 0,0359 & $* *$ \\
\hline FIPEZAP_Res_Venda & 8,09708 & \multicolumn{2}{|c|}{3,26448} & 2,4804 & 0,0199 & $* *$ \\
\hline IBO & 0,303979 & \multicolumn{2}{|c|}{0,0911335} & 3,3355 & 0,0026 & $* * *$ \\
\hline Média var. dependente & \multicolumn{2}{|c|}{1,481156} & \multicolumn{2}{|c|}{ D.P. var. dependente } & \multicolumn{2}{|c|}{3,674563} \\
\hline Soma resíd. quadrados & \multicolumn{2}{|c|}{256,1465} & \multicolumn{2}{|c|}{ E.P. da regressão } & \multicolumn{2}{|c|}{3,138756} \\
\hline R-quadrado & \multicolumn{2}{|c|}{0,345847} & \multicolumn{2}{|c|}{ R-quadrado ajustado } & \multicolumn{2}{|c|}{0,270368} \\
\hline$F(3,26)$ & \multicolumn{2}{|c|}{5,661367} & \multicolumn{2}{|c|}{ P-valor(F) } & \multicolumn{2}{|c|}{0,004016} \\
\hline Log da verossimilhança & \multicolumn{2}{|c|}{$-74,73644$} & \multicolumn{2}{|c|}{ Critério de Akaike } & \multicolumn{2}{|c|}{157,4729} \\
\hline Critério de Schwarz & \multicolumn{2}{|c|}{163,0777} & \multicolumn{2}{|c|}{ Critério Hannan-Quinn } & \multicolumn{2}{|c|}{159,2659} \\
\hline Rô & \multicolumn{2}{|c|}{$-0,290789$} & \multicolumn{2}{|c|}{ Durbin-Watson } & \multicolumn{2}{|c|}{2,565921} \\
\hline $\begin{array}{l}\text { Teste de White para } \\
\text { Hipótese nula: sem } \\
\text { Estatística de teste: } \\
\text { com p-valor = P(Qui- }\end{array}$ & $\begin{array}{l}\text { teroscedastic } \\
\text { oscedasticida } \\
13,1837 \\
\text { rado(9) > 13, }\end{array}$ & ade - & 15447 & & & \\
\hline
\end{tabular}

Fonte: Elaborado pelos autores no software Gretl. 
Nota-se que com a estimação do novo modelo de regressão stepwise, as variáveis explanatórias FIPEZAP_Res_Venda e O IBO têm impacto positivo no IFIX, mas o FIPEZAP_Com_Loc. tem impacto negativo. Isso significa que a cada 1,0000\% de aumento no índice Ibovespa, há um aumento de 0,3040\% nos Fundos Imobiliários; a cada 1,0000\% de aumento no coeficiente FIPEZAP_Res_Venda, há um aumento de 8,09708\% nos Fundos Imobiliários; a cada 1\% de aumento no FIPEZAP_Com_Loc, há uma redução de $-1,0543 \%$ nos Fundos Imobiliários.

No período de junho de 2015 a dezembro de 2017, o FIPEZAP_Res_Venda apresentou forte influência na variação do IFIX. Uma possível explicação é que valorização dos imóveis residenciais leva à valorização das quotas dos Fundos Imobiliários, as quais refletem o valor de mercado dos imóveis geridos.

Uma possível explicação para a relação negativa entre o IFIX e o Índice FIPEZAP_Com._Loc é que exista uma concorrência entre os investimentos em imóveis comerciais e em Fundos Imobiliários. Dessa forma, o aumento no valor das locações comerciais faz com que os investidores direcionem recursos para a compra destes imóveis, diminuindo a demanda pelos Fundos Imobiliários e desvalorizando suas quotas. O teste de White novamente não rejeita a hipótese nula de Homoscedasticidade e o Fator de Inflacionamento da Variância não indicou problemas de multicolinearidade.

\section{CONSIDERAÇÕES FINAIS}

Com o aumento dos valores dos imóveis, aplicar recursos diretamente neste setor inviável para muitos investidores. Em síntese, diversos fatores mercadológicos proporcionaram maior visibilidade para os investimentos em Fundos Imobiliários pelas suas vantagens operacionais.

O desenvolvimento do presente estudo possibilitou uma análise do risco-retorno dos Fundos Imobiliários. Além disso, também permitiu uma pesquisa aplicada com coleta de dados de variáveis para obter dados mais consistentes sobre o tema. Neste contexto, após a estimação da regressão stepwise, é possível afirmar que o retorno dos Fundos Imobiliários Brasileiros é influenciado principalmente pelo Índice Ibovespa.

A quebra estrutural existente em 2015 indica uma mudança na dinâmica da formação do IFIX. Na subamostra que inicia a partir de 2015, percebe-se que a valorização dos imóveis residenciais vendidos e as locações comerciais passam a exercer influência sobre o índice, momento marcado pela valorização dos Fundos Imobiliários. Não obstante, o índice Ibovespa passa a exercer maior influência, de forma que os investidores dos Fundos Imobiliários estão também sujeitos ao risco sistemático, o que pode ser considerado um ponto negativo deste produto. 
Os resultados encontrados se diferenciam dos trabalhos de Frade (2015), Scolese et al (2015), Manganotti (2014) por não encontrar relação significativa entre a taxa SELIC/CDI e os Fundos Imobiliários. Por outro lado, ressalta-se que os índices da FIPE utilizados como variáveis explanatórias neste trabalho podem ter substituído este efeito. Quanto à influência do Ibovespa, este estudo vai a entro de Scolese et al (2015) e Manganotti (2014), os quais também encontraram relação significativa e positiva.

Sugere-se que mais estudos sejam realizados futuramente, segregando os Fundos Imobiliários em categorias ao invés de utilizar um índice como proxy.

\section{REFERÊNCIAS}

ANDRADE, Maria Margarida de. Introdução à metodologia do trabalho científico. 10. Ed. São Paulo: Atlas, 2010.

ASSOCIAÇÃO BRASILEIRA DAS ENTIDADES DOS MERCADOS FINANCEIROS E DE CAPITAIS ANBIMA. Fundos de Investimentos Imobiliários. Estudos Especiais: Produtos de Captação. Rio de Janeiro, 2014. 144 p.

ASSOCIAÇÃO BRASILEIRA DAS ENTIDADES DOS MERCADOS FINANCEIROS E DE CAPITAIS ANBIMA. Boletim de Fundos de Investimento. Disponível em:

<http://www.anbima.com.br/pt_br/informar/relatorios/fundos-de-investimento/boletim-defundos-de-investimentos/multimercados-ampliam-base-de-investidores-em-2017.htm> Acesso em: 23 de setembro de 2018.

BUSSAB, Wilton de O.; MORETTIN, Pedro A. Estatística Básica. 6ạ ed. - São Paulo: Saraiva, 2010.

BMF\&BOVESPA. Fundos de Investimentos Imobiliários. Disponível em: < http://www.bmfbovespa.com.br/pt_br/produtos/listados-a-vista-e-derivativos/rendavariavel/fundos-de-investimento-imobiliario-fii.htm> Acesso em: 21/04/2018.

BRASIL. Lei no11.033, de 21 de dezembro de 2004. Altera a tributação do mercado financeiro e de capitais; institui o Regime Tributário para Incentivo à Modernização e à Ampliação da Estrutura Portuária - REPORTO; altera as Leis nos 10.865, de 30 de abril de 2004, 8.850, de 28 de janeiro de 1994, 8.383, de 30 de dezembro de 1991, 10.522, de 19 de julho de 2002, 9.430, de 27 de dezembro de 1996, e 10.925, de 23 de julho de 2004; e dá outras providências. Diário Oficial da República Federativa do Brasil. Brasília, DF, 22 de dez. de 2004.

BRASIL. Lei no11.196, de 21 de novembro de 2005. Institui o Regime Especial de Tributação para a Plataforma de Exportação de Serviços de Tecnologia da Informação - REPES, o Regime Especial de Aquisição de Bens de Capital para Empresas Exportadoras - RECAP e o Programa de Inclusão Digital; dispõe sobre incentivos fiscais para a inovação tecnológica; altera o Decreto-Lei ํㅡ 288, de 28 de fevereiro de 1967, o Decreto no 70.235 , de 6 de março de 1972, o Decreto-Lei no 2.287, de 23 de julho de 1986, as Leis nos 4.502, de 30 de novembro de 1964, 
8.212, de 24 de julho de 1991, 8.245, de 18 de outubro de 1991, 8.387, de 30 de dezembro de 1991, 8.666, de 21 de junho de 1993, 8.981, de 20 de janeiro de 1995, 8.987, de 13 de fevereiro de 1995, 8.989, de 24 de fevereiro de 1995, 9.249, de 26 de dezembro de 1995, 9.250, de 26 de dezembro de 1995, 9.311, de 24 de outubro de 1996, 9.317, de 5 de dezembro de 1996, 9.430, de 27 de dezembro de 1996, 9.718, de 27 de novembro de 1998, 10.336, de 19 de dezembro de 2001, 10.438, de 26 de abril de 2002, 10.485, de 3 de julho de 2002, 10.637, de 30 de dezembro de 2002, 10.755, de 3 de novembro de 2003, 10.833, de 29 de dezembro de 2003, 10.865, de 30 de abril de 2004, 10.925, de 23 de julho de 2004, 10.931, de 2 de agosto de 2004, 11.033, de 21 de dezembro de 2004, 11.051, de 29 de dezembro de 2004, 11.053, de 29 de dezembro de 2004, 11.101, de 9 de fevereiro de 2005, 11.128, de 28 de junho de 2005, e a Medida Provisória no 2.199-14, de 24 de agosto de 2001; revoga a Lei no 8.661, de 2 de junho de 1993, e dispositivos das Leis nos 8.668, de 25 de junho de 1993, 8.981, de 20 de janeiro de 1995, 10.637, de 30 de dezembro de 2002, 10.755, de 3 de novembro de 2003, 10.865, de 30 de abril de 2004, 10.931, de 2 de agosto de 2004, e da Medida Provisória no 2.158-35, de 24 de agosto de 2001; e dá outras providências. Diário Oficial da República Federativa do Brasil. Brasília, DF, 22 de nov. de 2005.

BRASIL. Lei no 8.668, de 25 de junho de 1993.

Dispõe sobre a constituição e o regime tributário dos Fundos de Investimento Imobiliário e dá outras providências. Diário Oficial da República Federativa do Brasil. Brasília, DF, 25 de jun. de 1993.

COSTA NETO, Pedro Luiz de Oliveira. Estatística. 3ạ ed. - São Paulo: Blucher, 2002.

COMISSÃO DE VALORES MOBILIÁRIOS. Guia CVM do investidor: Fundos de Investimento Imobiliário. 2ªed. Rio de Janeiro: Comissão de Valores Mobiliários, 2015. 20p. (Guia CVM 01).

COMISSÃO DE VALORES MOBILIÁRIOS. Instrução CVM n. 555, de 17 de dezembro de 2014, com as alterações introduzidas pelas instruções CVM № 563/15, 564/15, 572/15, 582/16 e 587/17. Dispõe sobre a constituição, a administração, o funcionamento e a divulgação de informações dos fundos de investimento.

COMISSÃO DE VALORES MOBILIÁRIOS. Instrução CVM no 472, de 31 de outubro de 2008, com as modificações introduzidas pelas instruções CVM no 478/09, 498/11, 517/11, 528/12, 554/14, 571/15 E 580/16. Dispõe sobre a constituição, a administração, o funcionamento, a oferta pública de distribuição de cotas e a divulgação de informações dos Fundos de Investimento Imobiliário - FII. Revoga as instruções CVM no 205, de 14 de janeiro de 1994, no 389, de 3 de junho de 2003, no 418, de 19 de abril de 2005 e no 455, de 13 de junho de 2007. Acrescenta o anexo III-B à instrução CVM no 400, de 29 de dezembro de 2003.

FIORINI, Renato Maestre. Determinantes da Rentabilidade dos Fundos de Investimento Imobiliários no Brasil. São Paulo, 2012, 73f. Disponível em:

<https://bibliotecadigital.fgv.br/dspace/.../Dissertacao_Renato_Fiorini_20121228.pdf> Acesso em: 21 de dezembro de 2017.

FONSECA, Nelson F.; BRESSAN, Aureliano A.; IQUIAPAZA, Robert A.; GUERRA, João Paulo. Análise do desempenho recente de Fundos de Investimento no Brasil. Contab. Vista \& Rev., v. 
18, n. 1, p. 95-116, jan./ mar. 2007. Disponível em:

<https://revistas.face.ufmg.br/index.php/contabilidadevistaerevista/article/view/321> Acesso em: 21 de dezembro de 2017.

FRADE, Rafael Berger. Avaliação da sensibilidade dos Fundos de Investimento Imobiliários à variações nas taxas de juros através da análise de componentes principais. Fundação Getúlio Vargas. São Paulo, 2015, 40 f. Disponível em:

<https://bibliotecadigital.fgv.br/dspace/.../Rafael\%20Frade\%20Versao\%20Final.pdf> Acesso em: 21 de dezembro de 2017.

GUJARATI, Damodar N.; PORTER, Dawn C. Econometria Básica. 5ạ ed. - São Paulo: AMGH, 2011.

GERHARDT, Tatiana Engel; SILVEIRA, Denise Tolfo. Métodos de Pesquisa. 1. ed. Porto Alegre: Editora da UFRGS, 2009.

GIL, Antônio Carlos. Como Elaborar Projetos de Pesquisa. 5.ed. São Paulo: Atlas, 2016.

GUIMARÃES, José Gustavo Macedo. Persistência na performance de Fundos de Investimento Imobiliário Brasileiros entre 2008 e 2012. Fundação Getúlio Vargas. Rio de Janeiro, 2013, $38 f$. Disponível em:

<https://bibliotecadigital.fgv.br/.../Persistência\%20na\%20performance\%20de\%20fundo> Acesso em: 21 de dezembro de 2017.

MOTA, Ronaldo Rodrigues. A evolução do mercado de Fundos de Investimentos Imobiliários no Brasil no período de 1994 a março/2013 e a utilização dessa alternativa de investimento para o investidor pessoa física no Brasil. Universidade de Brasília, 2013, 114 p. Disponível em: $<$ repositorio.unb.br/bitstream/10482/15165/1/2013_RonaldoRodriguesMota.pdf> Acesso em: 21 de dezembro de 2017.

MANGANOTTI, Karen Hiramatsu. Estudo sobre a ocorrência ou não de retorno anormal nos Fundos Imobiliários de Renda e a comparação com o retorno de imóveis físicos que propiciam renda. Universidade de São Paulo. São Paulo, 2014. Disponível em:

$<w w w . t e s e s . u s p . b r / t e s e s / d i s p o n i v e i s / 12 / 12139 /$ tde-11122014-153216/pt-br.php > Acesso em: 21 de dezembro de 2017.

MIZUNO, Jorge; DUCLÓS, Luis Carlos; SILVA, Wesley Vieira da; ROCHA, Daniela Torres da. Análise da eficiência dos fundos de investimentos imobiliários. Revista Pensamento Contemporâneo em Administração, vol. 5, núm. 1, janeiro-abril, 2011, pp. 66-79 Universidade Federal Fluminense Rio de Janeiro, Brasil. Disponível em: < www.uff.br/pae/pca/article/viewFile/21/30>. Acesso em: 21 de dezembro de 2017.

PAIS, Manuel Alexandre Pinto Caldeira. Valorização do Activo Imobiliário dos Fundos de Investimento Imobiliário Portugueses e suas características. Lisboa, 2011. Disponível em: <https://www.repository.utl.pt/handle/10400.5/3770> Acesso em: 21 de dezembro de 2017.

PITTA, Carlos Eduardo. Risco e Retorno do Investimento Imobiliário: Um estudo do Mercado 
de Imóveis Comerciais de São Paulo. Fundação Getúlio Vargas. São Paulo, 2000. Disponível em: <https://bibliotecadigital.fgv.br/dspace/bitstream/handle/10438/5892/1200001464.pd> Acesso em: 21 de dezembro de 2017.

SCOLESE, Daniel; BERGMANN, Daniel R.; SILVA, Fabiana Lopes da; SAVOIA, José Roberto F. Análise de estilo de fundos imobiliários no Brasil. Revista de Contabilidade e Organizações, vol. 9, núm. 23, 2015, pp. 24-35 Universidade de São Paulo São Paulo, Brasil. Disponível em: < http://dx.doi.org/10.11606/rco.v9i23.83452> Acesso em: 21 de dezembro de 2017.

SEVERINO, Antônio Joaquim. Metodologia do Trabalho Científico. 23. ed. São Paulo: Cortez, 2007.

TRIOLA, Mario F. Introdução à Estatística: atualização da tecnologia. Tradução da revista técnica Ana Maria Lima de Farias, Vera Regina Lima de Farias e Flores. 11a ed. - Rio de Janeiro: LTC, 2015.

TRINDADE, João Antônio de Souza; MALAQUIAS, Rodrigo Fernandes. Análise de desempenho de Fundos de Investimento de Renda Fixa e Renda Variável. RAGC. V.3, no5, p.76-95/2015. Disponível em: < Acesso em: 21 de dezembro de 2017.

VALIM, Vinicius Ziegler. Risco e Cuidados com Investimentos no Mercado Imobiliário. ISSN 2179-5568 - Revista Especialize On-line IPOG - Goiânia - 6a Edição no 006 Vol.01/2013 dezembro/2013. Disponível em: <https://www.ipog.edu.br/download-arquivo-site.sp?riscose-cuidados-com-investimentos-no-mercado-imobiliario> Acesso em: 21 de dezembro de 2017.

YOKOYAMA, Karen Yuraki. Os Fundos de Investimentos Imobiliários listados em bolsa e as variáveis que influenciam seus retornos. Vitória, 2014. Disponível em:

<http://repositorio.ufes.br/bitstream/10/1307/1/Dissertacao\%20Karen\%20Yuraki\%20Yokoya ma.pdf> Acesso em: 21 de dezembro de 2017. 